\title{
Brief outline on neurobiology of autistic spectrum disorders (ASD)
}

\begin{abstract}
Autism spectrum disorder (ASD) is a set of neuro developmental disorders which is characterized by lack of social behaviors and nonverbal interactions like visual impaired impairment including communication difficulties such as disturbed facial expression and impaired body gestures that starts early in childhood. It is multi-factorial disorder resulting from genetic and non-genetic risk factors and their interaction. Genetic studies of ASD have reported that identified mutations interfere with typical neurodevelopment in mother's womb through childhood and these complexes of genes have been further involved in synaptogenesis and axon motility. Recently, newly advanced neuro imaging studies have provided many important clinical data of their associated pathological changes that occur in the brain of ASD patients in vivo. Crucial role is played by amygdala that is a major component of the limbic system and the affective loop of the cortico-striato-thalamo-cortical circuit and their associated cognition with nucleus accumbens play important role in social behaviors. Their reported deficit in ASD patients has been proved for impaired social behaviors and poor cognitive stimulus that found interlinked in numerous neuro pathological and neuro imaging studies. Although educational and behavioral treatments are mostly considered the primary steps of the management of ASD along with its associated pharmacological and interventional treatments. Previously, some of reported data of few ASD patients have been studied for experiencing the improvements after deep brain stimulation as one of the interventional treatments. The key bone of neurobiology of ASD development is still a target for its treatment and medical management that is required to broaden its clinical horizons to understand ASD.
\end{abstract}

Keywords: ASD, neurobiology, amygdale, accumbens, NAC, teratogens
Volume 5 Issue I - 2018

Kirti Rani
Department of Biotechnology, Amity University, India

Correspondence: Kirti Rani, Assistant Professor (III),Amity Institute of Biotechnology,

Amity University Uttar Pradesh, Noida, Sec-125, Gautam

Buddha Nagar, Noida-20 303 (UP), India, Tel +91-120-4392946, $+91-9990329492$

Email krsharma@amity.edu, Kirtisharma2k@rediffmail.com

Received: October 30, 2017| Published: February 20, 2018

\section{Introduction}

Autism spectrum disorder (ASD) is a set of neuro developmental disorders characterized by a lack of social interaction, verbal and nonverbal communication which is noticed in the first 3 years of childhood. The distinctive social behaviors include an avoidance of eye contact, fluctuate emotional control and difficulties in understanding the emotions of other people. ${ }^{1,2}$ Increase in prevalence of ASD have been reported and higher rate is found in males than females partially the result of changes in DSM diagnostic criteria and younger age of diagnosis, an increase in risk factors cannot be ruled out. ${ }^{3,4}$ Crucial role is played by amygdale, prefrontal lobe and nucleus accumbens that is a major component of the limbic system and the affective loop of the cortico-striato-thalamo-cortical circuit and their associated deficit cognition reported for impaired social behaviors in ASD patients. Studies have shown a male predominance; ASD affects $2 \sim 3$ times more males than females. ${ }^{5,6}$ ASD is clinically diagnosed on the basis of the presence of its associated non-specific manifestation like individual abilities in intelligence and verbal domains. The onsets of nonspecific manifestation are notices in infants or toddlers such as irritability, passivity, and difficulties with sleeping and eating, followed by delays in language and social involvement. ${ }^{6,7}$

\section{Etiology}

ASD is broadly considered to be a multi-factorial disorder resulting from genetic and non-genetic risk factors and their interaction along with various diverse environmental causative elements including pre-natal, perinatal, and post-natal factors that contribute ASD. ${ }^{7}$ Previously, various prenatal factors are found to related with ASD such as exposure to teratogens such as thalidomide, certain viral infections (congenital rubella syndrome), maternal anticonvulsants such as valproic acid as well as low birth weight, abnormally short gestation length and birth asphyxia are considered the perinatal factors. ${ }^{8,9}$

\section{Clinical features}

ASD in children is also manifested with non-specific symptoms such as unusual sensory perception skills, motor clumsiness and insomnia along with associated phenomena like mental retardation, emotional indifference, hyperactivity, aggression, self-injury and repetitive/stereotyped behaviors such as body rocking or hand flapping. ${ }^{10}$ Repetitive behaviors are often accompanied by cognitive impairment, seizures or epilepsy, gastrointestinal complaints, disturbed sleep, and other problems whose differential diagnosis reported for various associated disorders such as childhood schizophrenia, learning disability and deafness. ${ }^{3,11}$

\section{Diagnosis}

ASD is clinically diagnosed on the basis of the presence of its associated core symptoms especially non-specific manifestation of individual abilities in intelligence and verbal domains. ${ }^{11}$ The onsets of nonspecific signs are recognized in infants or toddlers include irritability, passivity, and difficulties with sleeping and eating, followed by delays in language and social engagement. However, some clinicians/researchers have reported that about $50 \%$ of infants show 
behavioral abnormalities or atypical behaviors including extremes of temperament, impaired visual contact, fluctuated emotional control, lack of response to parental voices or interaction, imitation, social responses and motor control. ${ }^{11,12}$ The frontal and temporal lobes are the markedly affected brain areas in ASD patients especially the reported role of amygdala in cognition and ASD that have been studied from numerous neuro pathological and neuro imaging reports. The amygdala is a major component of the limbic system and affective loop of the cortico-striato-thalamo-cortical circuit and its deficit in ASD patients is reported for abrupt social and aggressive behavior. ${ }^{12,13}$ Prefrontal lobe has been considered as playing an important role in higher-level control and a key bone structure associated with autism and its deficit demonstrate higher-order cognitive, language, social, and emotion dysfunction, which is deficient in ASD patients..$^{14,15}$ Besides amygdala, nucleus accumbens (NAc) is also considered as the key point structure which is found to deficit in ASD patients to have impaired social reward and pleasure response in ASD. ${ }^{16,17}$

\section{Treatment}

An ASD Medical management criterion in patients includes typical antipsychotics, atypical antipsychotics, antidepressants, selective serotonin reuptake inhibitors, $\alpha 2$-adrenergic agonists, $\beta$-adrenergic antagonist, mood stabilizers and anticonvulsants. ${ }^{17,18}$ Antidepressants were the most commonly prescribed agents followed by other stimulants and antipsychotics for ASD patients. The high prevalence of comorbidities is found to reflect in the rates of psychotropic medication used in some of ASD patients. Antipsychotics were effective in treating the repetitive behaviors in children with ASD; however, there was not sufficient evidence on the efficacy and safety in adolescents and adults. ${ }^{18,19}$ There are also alternative medication which are chosen by some of physicians includes opiate antagonist, immunotherapy, hormonal agents, megavitamins and other dietary supplements. ${ }^{19,20}$

\section{Conclusion}

So, this brief review could be helpful to sort the outline of neurobiology of Autism Spectrum Disorder (ASD) and its associated disorders and non-specific manifestations. The causes of ASD are not still known and various conducted researches suggest that both genes and environment play important roles to develop this neurodevelopment disorder. There is currently no one standard medical treatment that used in clinical management of ASD in affected population. Although, proposed treatments is used to treat ASD including behavior and communication therapies, skills training, and use of opiate antagonist, immunotherapy, hormonal agents, megavitamins, other dietary supplements or medicines that proposed to increase affected child's ability to grow and learn new skills to achieve better results to control its associated symptoms.

\section{Acknowledgements}

None.

\section{Conflict of interest}

The author declares no conflict of interest.

\section{References}

1. Mattila ML, Kielinen M, Linna SL, et al. Autism spectrum disorders according to DSM-IV-TR and comparison with DSM-5 draft criteria: an epidemiological study. J Am Acad Child Adolesc Psychiatry. 2011;50(6):583.e.11-592.
2. Kim YS, Leventhal BL, Koh YJ, et al. Prevalence of autism spectrum disorders in a total population sample. Am $J$ Psychiatry. 2011;168(9):904-912.

3. Elsabbagh M, Divan G, Koh YJ, et al. Global prevalence of autism and other pervasive developmental disorders. Autism Res. 2012;5(3):160 179.

4. Fombonne E. Incidence and prevalence of pervasive developmental disorders. In: Hollander E, et al. editors. Textbook of autism spectrum disorders. Washington, USA: American Psychiatric Publishing; 2011. p. 117-136.

5. London EA. The environment as an etiologic factor in autism: a new direction for research. Environ Health Perspect. 2000;108(Suppl 3):401404.

6. Kern JK, Jones AM. Evidence of toxicity, oxidative stress, and neuronal insult in autism. J Toxicol Environ Health B Crit Rev. 2006;9(6):485499.

7. Kolevzon A, Gross R, Reichenberg A. Prenatal and perinatal risk factors for autism: a review and integration of findings. Arch Pediatr Adolesc Med. 2007;161(4):326-333.

8. Davidson PW, Myers GJ, Weiss B. Mercury exposure and child development outcomes. Pediatrics. 2004;113(4 Suppl):1023-1029.

9. Bessette Gorlin J, McAlpine CP, Garwick A, et al. Severe childhood autism: the family lived experience. J Pediatr Nurs. 2016;31(6):580-597.

10. Fakhoury M. Autistic spectrum disorders: A review of clinical features, theories and diagnosis. Int J Dev Neurosci. 2015;43:70-77.

11. Zwaigenbaum L, Bryson S, Rogers T, et al. Behavioral manifestations of autism in the first year of life. Int J Dev Neurosci. 2005;23(2-3):143152 .

12. Sah P, Faber ES, Lopez De Armentia M, et al. The amygdaloid complex: anatomy and physiology. Physiol Rev. 2003;83(3):803-834.

13. Alexander GE, DeLong MR, Strick PL. Parallel organization of functionally segregated circuits linking basal ganglia and cortex. Annu Rev Neurosci. 1986;9:357-381.

14. Stuss DT, Knight RT. Principles of frontal lobe function. USA: Oxford University Press; 2013.

15. Mashhoon Y, Wells AM, Kantak KM. Interaction of the rostral basolateral amygdala and prelimbic prefrontal cortex in regulating reinstatement of cocaine-seeking behavior. Pharmacol Biochem Behav. 2010;96(3):347-353.

16. Knutson B, Adams CM, Fong GW, et al. Anticipation of increasing monetary reward selectively recruits nucleus accumbens. J Neurosci. 2001;21(16):RC159.

17. Stigler KA, McDonald BC, Anand A, et al. Structural and functional magnetic resonance imaging of autism spectrum disorders. Brain Res. 2011;1380:146-161.

18. Farmer C, Thurm A, Grant P. Pharmacotherapy for the core symptoms in autistic disorder: current status of the research. Drugs. 2013;73(4):303314.

19. Jacob Kerbeshian, Larry Burd, Karilyn Avery. Pharmacotherapy of autism: A review and clinical approach. Journal of Developmental and Physical Disabilities. 2001;13(3):199-228.

20. McPheeters ML, Warren Z, Sathe N, et al. A systematic review of medical treatments for children with autism spectrum disorders. Pediatrics. 2011;127(5):e1312-e1321. 